\title{
Reduction of Heparin and Oxidative Potential by Means of Citrasate in High-Flux Dialysis (HFD) and Online Hemodiafiltration (olHDF) in Pre and Postdilution
}

\author{
Roland E. Winkler, Peter Ahrenholz, \\ Wolfgang Paetow, Grit Waitz and Hartmut Wolf \\ Additional information is available at the end of the chapter \\ http://dx.doi.org/10.5772/52037
}

\section{Introduction}

Citrasate $^{\circledR}$ is a new innovative dialysis acid concentrate, in which $3 \mathrm{mmol} / \mathrm{l}$ of acetic acid have been replaced by $0.8 \mathrm{mmol} / \mathrm{l}$ of citric acid along with $0.3 \mathrm{mmol} / \mathrm{l}$ of acetate.

Using citrate-containing dialysate, a reduction of the heparin dose by up to 55\% was described in the literature (Kossmann et al., 2006, 2009). At the same time, the efficacy of dialysis was found to be increased. A local anticoagulation inside the dialyzer was supposed to be the reason, caused by a strong decrease of free calcium ions. A diminished thrombus formation inside the dialyzer should allow a higher mass transport across the membrane. The reduction of acetate concentration in the dialysate was found to increase the hemodynamic stability of hypertensive patients (Gabutti et al., 2009). So far, the question has not been investigated whether the reduction of acetate diminishes the inflammatory potential of acetate in such a way that the activation of thrombocytes and leucocytes as well as the release of cytokines will be reduced. Until now, a reduction of beta-2-microglobulin (beta-2-m) was observed, which could be attributed to an improved permeability of the membrane (Kossmann et al., 2009). The possible reduction of heparin by means of Citrasate ${ }^{\circledR}$ during chronic hemodialysis could lead to an economical benefit. The clinical benefit for patients would consist of the reduction of described side effects of acetate and heparin. Because of the small number of publications, it makes sense to verify the previous results and to check if the observed reduction of beta-2-m could be caused also by a reduction of oxidative potential in case of Citrasate ${ }^{\circledR}$ application.

Therefore the following questions should be answered: 
- Is it possible to reduce the dosage of heparin by means of Citrasate ${ }^{\circledR}$ for chronic dialysis treatments remaining the efficacy of treatment $(\mathrm{Kt} / \mathrm{V})$, and without increasing clotting events in dialyzer and extracorporeal circuit?

- Which impact of Citrasate ${ }^{\circledR}$ can be found on the reduction of inflammatory and oxidative potential measured by the following parameters: plasma concentration of beta-2-m, hsCRP, prealbumin and myeloperoxidase (MPO)? Recently, MPO was described as a suitable marker for oxidative stress during acute dialysis treatment (Maruyama et al., 2004).

- Which influence can be observed on the plasma level of phosphate and ionized calcium as a result of application of Citrasate ${ }^{\circledR}$ ?

In addition to the High-flux Dialysis study (HFD), it should be investigated if Citrasate ${ }^{\circledR}$ concentrate can be used also for on-line hemodiafiltration (olHDF). Because the infusate for olHDF will be prepared directly from the dialysate, the use of Citrasate ${ }^{\circledR}$ dialysate means the infusion of a considerable amount of citrate directly into the blood. Using olHDF in predilution mode, the substitution fluid will be infused into the blood stream before the dialyzer, meaning citrate will be included in the mass transfer processes of the dialyzer. During olHDF in postdilution mode, the citrate- containing fluid is infused into the peripheral blood behind the dialyzer. Since the effects of Citrasate ${ }^{\circledR}$ on free calcium ion concentration and coagulation system cannot predicted precisely, Citrasate ${ }^{\circledR}$ should be applied at first in the predilution mode of olHDF, and only later in the postdilution mode.

During the Citrasate ${ }^{\circledast}$ application in olHDF, the focus should be directed to the following questions:

- Is it possible to maintain a reduced heparin dose?

- Can the influence of Citrasate ${ }^{\circledR}$ on coagulation processes inside the dialyzer increase the efficacy of dialysis?

- Is it possible to reduce MPO activation?

- Will the plasma concentrations of calcium and phosphate stay in the physiologically optimal range?

\section{Materials and methods}

\subsection{Time schedule}

The HFD part of the investigation was conducted with the following time schedule:

Weeks 1-2: Measurement of parameters specified below, with standard dialysate and heparin dosage (baseline).

Weeks 3-6: Change to Citrasate ${ }^{\circledR}$ without any change in other treatment conditions.

Weeks 7-10: Dialysis with Citrasate ${ }^{\circledR}$ and $50 \%$ reduction of heparin bolus. 
Weeks 11-14: Dialysis with Citrasate ${ }^{\circledR}$ and $50 \%$ reduction of bolus and maintenance amount of heparin resulting in $50 \%$ total reduction of heparin.

Afterwards, the investigation was continued with olHDF:

Week 1: Measurement of parameters mentioned below during HFD with Citrasate ${ }^{\circledR}\left(\mathrm{Ca}^{2+}: 1.5\right.$ $\mathrm{mmol} / \mathrm{l}$ ) using the reduced $50 \%$ heparin dose (bolus $-50 \%$ and maintenance dose $-50 \%$ ).

Weeks 2-3: Change to olHDF predilution (substitution rate: $150 \mathrm{ml} / \mathrm{min}$ ) with Citrasate $^{\circledR}\left(\mathrm{Ca}^{2+}\right.$ : $1.5 \mathrm{mmol} / \mathrm{l})$.

Weeks 4-5: olHDF predilution as described above, but with standard concentrate $\left(\mathrm{Ca}^{2+}: 1.25\right.$ $\mathrm{mmol} / \mathrm{l})$.

Weeks 6-7: Change to olHDF postdilution (substitution rate: $60 \mathrm{ml} / \mathrm{min}$ ) with Citrasate $^{\circledR}\left(\mathrm{Ca}^{2+}\right.$ : $1.5 \mathrm{mmol} / \mathrm{l})$.

Weeks 8-9: olHDF postdilution as described above, but with standard concentrate $\left(\mathrm{Ca}^{2+}: 1.25\right.$ $\mathrm{mmol} / \mathrm{l})$.

\subsection{Materials}

The following types of standard concentrate were used, differing only in the $\mathrm{K}^{+}$-concentration ( 3.0 or $4.0 \mathrm{mmol} / \mathrm{l}$, respectively): Concentrations of final mixed dialysate:

\begin{tabular}{llllllll}
\hline $\mathrm{Na}^{+}$ & $\mathbf{K}^{+}$ & $\mathrm{Ca}^{2+}$ & $\mathbf{M g}^{2+}$ & $\mathrm{Cl}^{-}$ & Acetate & $\mathbf{H C O}_{3}{ }^{-}$ & Glucose \\
\hline $\mathrm{mmol} / /$ & $\mathrm{mmol} / \mathrm{l}$ & $\mathrm{mmol} / \mathrm{l}$ & $\mathrm{mmol} / \mathrm{l}$ & $\mathrm{mmol} / \mathrm{l}$ & $\mathrm{mmol} / \mathrm{l}$ & $\mathrm{mmol} / \mathrm{l}$ & $\mathrm{g} / \mathrm{l}$ \\
\hline 138 & $3.0 / 4.0$ & 1.25 & 0.75 & 110.0 & 2.00 & 33 & 1.0 \\
\hline
\end{tabular}

Table 1.

The following types were used for treatments with Citrasate ${ }^{\circledR}$ :

\begin{tabular}{llllllllll}
\hline Type & $\mathbf{N a}^{+}$ & $\mathbf{K}^{+}$ & $\mathbf{C a}^{2+}$ & $\mathbf{M g}^{2+}$ & $\mathrm{Cl}^{-}$ & Acetate & Citrate & $\mathbf{H C O}_{3}{ }^{-}$ & $\mathbf{G}$ lucose \\
\hline $\mathrm{MTN}$ & $\mathrm{mmol} / \mathrm{l}$ & $\mathrm{mmol} / \mathrm{l}$ & $\mathrm{mmol} / \mathrm{l}$ & $\mathrm{mmol} / \mathrm{l}$ & $\mathrm{mmol} / \mathrm{l}$ & $\mathrm{mmol} / \mathrm{l}$ & $\mathrm{mmol} / \mathrm{l}$ & $\mathrm{mmol} / \mathrm{l}$ & $\mathrm{g} / \mathrm{l}$ \\
\hline 413 & 135.3 & 3.0 & $1.25 / 1.50$ & 0.50 & 107.0 & 0.30 & 0.80 & 32.60 & 1.0 \\
\hline 415 & 135.3 & 4.0 & $1.25 / 1.50$ & 0.50 & 111.0 & 0.30 & 0.80 & 32.60 & 1.0 \\
\hline
\end{tabular}

Table 2.

The treatments were performed with dialysis machines of type FMC 5008 (autoflow deactivated for olHDF treatments).

The following FMC-high-flux dialyzers were used for hemodialysis: FX60, FX80 and FX100. The blood flow was equal to $\mathrm{Q}_{\mathrm{B}}=300 \mathrm{ml} / \mathrm{min}$. Unfractionated heparin brand "Heparin sodium 5000 ratiopharm" was applied for anticoagulation. 


\subsection{Patients and heparin dosages}

Ten patients were selected from the running dialysis program fulfilling sufficient inclusion and exclusion criteria. All specific data of patients and used heparin dosages are included in the table "patient's data" (see table 1).

\begin{tabular}{|c|c|c|c|c|c|c|c|c|c|c|c|}
\hline No. & Sex & Age & $\begin{array}{c}\text { Time } \\
\mathrm{h}\end{array}$ & Dialyzer & $\begin{array}{c}\text { Body } \\
\text { mass/kg }\end{array}$ & $\begin{array}{c}\text { Hep.bolus } \\
\text { IU }\end{array}$ & $\begin{array}{c}\text { Hep./h } \\
\text { IU }\end{array}$ & $\begin{array}{c}\text { Total } \\
\text { hep./IU }\end{array}$ & $\begin{array}{c}\text { Hep.bolus } \\
\left.\text { theor. }^{\star}\right)\end{array}$ & $\begin{array}{l}\text { Hep.rate } \\
\text { theor.* }\end{array}$ & $\begin{array}{l}\text { Total hep. } \\
\text { theor*/IU }\end{array}$ \\
\hline 1 & $f$ & 68 & 4.0 & FX60 & 50.0 & 4000 & 1000 & 7500 & 1340 & 1750 & 7465 \\
\hline 2 & $f$ & 79 & 4.0 & FX80 & 58.0 & 2000 & 250 & 2875 & 1420 & 1750 & 7545 \\
\hline 3 & $\mathrm{~m}$ & 78 & 4.0 & FX60 & $8 ., 0$ & 3000 & 750 & 5625 & 1430 & 1750 & 7555 \\
\hline 4 & $f$ & 65 & 4.0 & FX60 & 61.5 & 2000 & 500 & 3750 & 1455 & 1750 & 7580 \\
\hline 5 & $f$ & 75 & 5.0 & FX100 & 76.5 & 2500 & 500 & 4750 & 1605 & 1750 & 9480 \\
\hline 6 & $m$ & 68 & 4.5 & FX60 & 82.0 & 3000 & 750 & 6000 & 1660 & 1750 & 8660 \\
\hline 7 & f & 87 & 4.0 & FX60 & 65.5 & 2500 & 625 & 4688 & 1195 & 1750 & 7320 \\
\hline 8 & $\mathrm{~m}$ & 76 & 5.0 & FX80 & 75.0 & 2500 & 500 & 4750 & 1290 & 1750 & 9165 \\
\hline 9 & $f$ & 57 & 5.0 & FX60 & 68.5 & 2500 & 500 & 4750 & 1225 & 1750 & 9100 \\
\hline 10 & $\mathrm{~m}$ & 87 & 4.0 & FX60 & 62.5 & 2500 & 625 & 4688 & 1465 & 1750 & 7590 \\
\hline
\end{tabular}

Table 3. Enrolled patients and administered heparin dosages, compared with theoretically proposed dosages (Ouseph/Ward formula)

The heparin dosages before study start were optimized by regarding bleeding time and clotting behavior. The theoretical heparin doses were calculated by means of the Ouseph/Wardformula (Ouseph et al., 2000):

$$
\text { Heparin-Bolus }(\mathrm{IU})=1600+10^{*}(\mathrm{BW}-76)-300^{*} \mathrm{Fd}-100 * \mathrm{Fs}
$$

Infusion Rate $(\mathrm{IU} / \mathrm{h})=1750$

BW: body mass $(\mathrm{kg}), \mathrm{Fd}=1$ diabetic, $\mathrm{Fd}=0$ non diabetic, $\mathrm{Fs}=1$ smoker, $\mathrm{Fs}=0$ non smoker.

The applied heparin doses during the baseline treatments were lower than theoretically proposed.

Two patients had to be excluded from the study after 7 weeks because of hospitalization. Another patient dropped out during the olHDF postdilution phase.

\subsection{Measured parameters}

Based on the HFD results, during the olHDF investigations some changes regarding the measured parameters were used: 
No measurements of blood cell counts, albumin, hsCRP, but addition of iPTH measurements. Beta-2-microglobulin (beta-2-m) was measured before and after treatment, because the reduction rate of beta-2-m can be used as a measure for the efficacy of medium-sized molecule clearance. Instead of ACT, the activated prothrombin time (aPTT) was measured because of its higher reliability.

\begin{tabular}{|c|c|}
\hline Parameter & Period of measurement \\
\hline Ionized Calcium & before and after each treatment \\
\hline Total Calcium & before and after each treatment - 1x per week \\
\hline Bicarbonate & before and after each treatment \\
\hline $\mathrm{pH}$ & before and after each treatment \\
\hline $\mathrm{Na}^{+}$ & before and after each treatment \\
\hline $\mathrm{K}^{+}$ & before and after each treatment \\
\hline Thrombocyte count & 1x per week, before, after 15 min and after treatment \\
\hline Leucocyte count & $1 \times$ per week, before, after $15 \mathrm{~min}$ and after treatment \\
\hline Phosphate & before and after each treatment $-1 \times$ per week \\
\hline ACT & 1x per week, before, after $15 \mathrm{~min}$ and after treatment \\
\hline $\mathrm{Kt} / \mathrm{V}$ & once per month \\
\hline beta-2-microglobulin pre-dialysis & once per month \\
\hline Albumin pre-dialysis & once per month \\
\hline hsCRP pre-dialysis & once per month \\
\hline Weekly EPO [TN: please define] dose & each week \\
\hline Weekly iron dose & each week \\
\hline Myeloperoxidase (MPO) & $\begin{array}{l}2 x \text { during each period of study before, after } 15 \text { min and after } \\
\text { treatment [TN: isn't that rather } 3 x \text { than } 2 x \text { ?] }\end{array}$ \\
\hline
\end{tabular}

Table 4. Parameters to be measured

\subsection{Analysis of data and statistical methods}

The analysis of data was performed by means of Microsoft-Excel-Software.WinStat for Excel and SigmaStat were used for descriptive statistics. All parameters are shown as mean values and with standard error of the mean (SEM).

Differences between measured values during different treatment modes were evaluated by ttest for paired samples. The Mann-Whitney test (U-test) was used in case normal distribution was lacking. A p-value $<0.05$ was considered statistically significant. Since the investigation had to be discontinued for 2 patients, their measured values were not included in the analysis.

Because of the change on hematocrit values during treatment, the measured plasma values $\left(\mathrm{Ca}^{2+}\right.$, phosphate, MPO) had to be corrected according to the following formula (van Beaumont, 1972): 


$$
\mathrm{C}_{\text {corr }}=\mathrm{c}_{*}(\text { Hcto/Hctn }) *(1-\text { Hctn }) /(1-\text { Hcto })
$$

Hcto $=$ hematocrit before treatment

Hctn $=$ hematocrit during sampling time $\mathrm{n}$

Measured values related to total blood volume (thrombocyte and leucocyte count) were corrected to reflect the change in hematocrit value:

$$
\mathrm{c}_{\mathrm{corr}}=\mathrm{c}_{*}(\text { Hcto/Hctn })
$$

According to the manufacturer's information (Radiometer), the ionometer values ( $\mathrm{pH}, \mathrm{Ca}^{2+}$, $\mathrm{Na}^{+}$und $\mathrm{K}^{+}$) do not have to be corrected because ion activities are measured (Christiansen, 1991).

If Hct-values were not available (olHDF treatments), post-treatment concentrations (Total-Ca, phosphate, beta-2-m, MPO) were corrected using the plasma volume reduction by ultrafiltration by means of the Bergström-formula:

$$
\mathrm{c}_{\text {corr }}=\mathrm{c}_{*}\left(1 /\left(1+\Delta \mathrm{BW} / 0.2 \mathrm{BW}_{\text {post }}\right)\right.
$$

$\triangle \mathrm{BW}$ : change of body mass, $\mathrm{BW}_{\text {post }}$ : body mass after treatment

\section{Results and discussion}

\subsection{High-Flux Dialysis (HFD)}

\subsubsection{Efficacy of dialysis in dependence on the heparin dose}

When performing hemodialysis with Citrasate $^{\circledR}$, it is assumed that the citrate causes a local anticoagulation inside the dialyzer because of chelation of ionized calcium. This process should be reflected by measurements of coagulation parameters like the "activated clotting time (ACT)". In fig. 1, the mean values of ACT measurements are shown before dialysis but after heparin bolus, after $15 \mathrm{~min}$ and after the end of treatment during the different periods of study (baseline: HD with standard concentrate, $50 \%$ heparin reduction in the bolus, $50 \%$ reduction of total heparin dose). Obviously, the influence of citrate-containing concentrate is not strong enough to achieve significant ACT changes in comparison to standard dialysate. After reduction of heparin in the bolus and in the maintenance dose, however, the changes in ACT are significant.

The possibility to reduce the heparin dose by using Citrasate ${ }^{\circledR}$ without incurring clotting events was in agreement with results of other authors (Kossmann et al., 2006: -55\%; Ahmad et al., 2006: $-30 \%$, Sands et al., 2012: -33\%). An improvement of efficacy, especially concerning the value of 


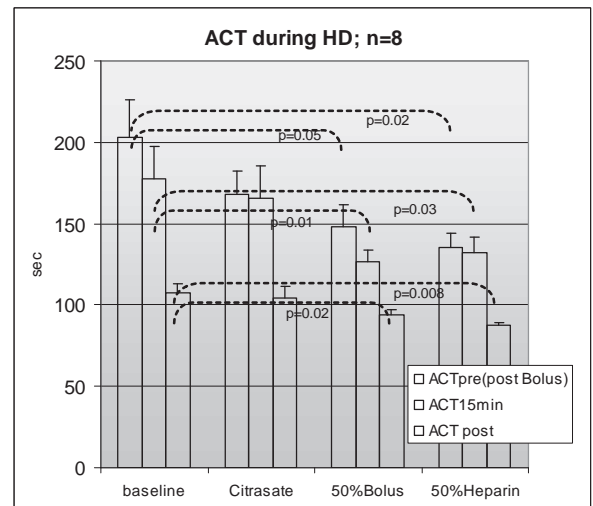

Figure 1. Activated clotting time pre dialysis, after $15 \mathrm{~min}$ and post dialysis during the different study phases: baseline (standard concentrate), Citrasate instead of standard concentrate (treatment conditions unchanged), Citrasate ${ }^{*}$ with reduction of the heparin bolus by $50 \%$, Citrasate with total heparin dose reduced by $50 \%$.

Kt/V and elimination of beta-2-m, was detected as well (Kossmann et al., 2009, Sands et al., 2012). These results could not be confirmed in our investigations. Fig. 2 illustrates the values of spKt/V and eqKt/V (calculated using the Daugirdas formula) for the different study periods. The change from standard concentrate to Citrasate ${ }^{\circledR}$ has shown constant efficacy of dialysis, whereas the reduction of heparin dosage resulted in a non-significant decrease of $\mathrm{Kt} / \mathrm{V}$. This result was in agreement with data of Ahmad et al. (2006) while the investigations of Kossmann et al. (2009) and Ahmad et al. (2000) resulted in a significant increase of Kt/V using Citrasate ${ }^{\circledR}$ even after the reduction of heparin. These investigations, however, were performed with reuse of dialyzers. The increase of Kt/V was found to be dependent on the number of reuses. The smaller thenumber of reuses the smaller the increase of $\mathrm{Kt} / \mathrm{V}$. Exact data, however, were not given.

Also, the values of beta-2-m do not indicate an improvement of treatment efficacy due to use of Citrasate® (see fig. 3), in contrast to the results of Kossmann et al. (2009).

With regard to the $\mathrm{HCO}_{3}{ }^{-}$concentrations before and after dialysis, it was found that both values were somewhat lower $(4 \ldots 5 \%)$ if Citrasate ${ }^{\circledR}$ was applied. This is due to the slightly smaller $\mathrm{HCO}_{3}{ }^{-}$concentration in the Citrasate ${ }^{\circledR}$ concentrate $(32.6 \mathrm{mmol} / 1$ instead of $33.0 \mathrm{mmol} / \mathrm{l}$ for standard concentrate).

Changes in the electrolytes $\mathrm{Na}^{+}$and $\mathrm{K}^{+}$before and after treatment could not be observed during the different periods of investigation.

\subsubsection{The influence of Citrasate ${ }^{\circledR}$ on inflammatory and oxidative potential}

The typical temporary drop in leucocyte count after start of dialysis treatments was found to be associated with the activation of complement factors C3a and C5a (Craddock et al., 1977). A decrease of iCa inside the dialyzer should be followed by a smaller complement activation and smaller leucocyte drop because of the importance of ionized calcium (iCa) in the cascade of complement activation. This effect, however, was not observed under the conditions of pure 


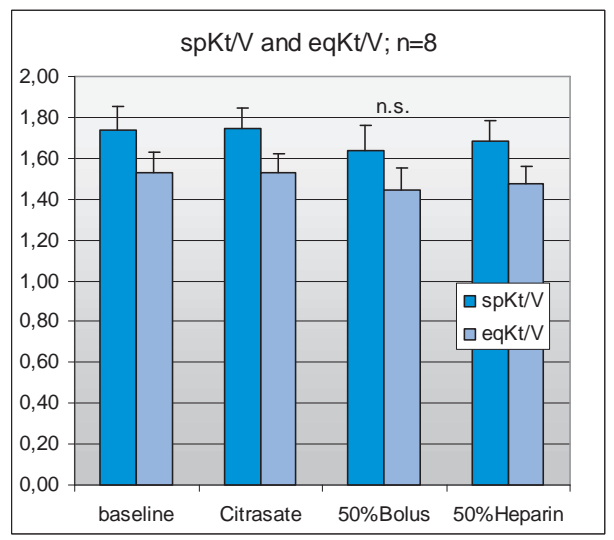

Figure 2. Single pool and equilibrated Kt/V during the different study phases.

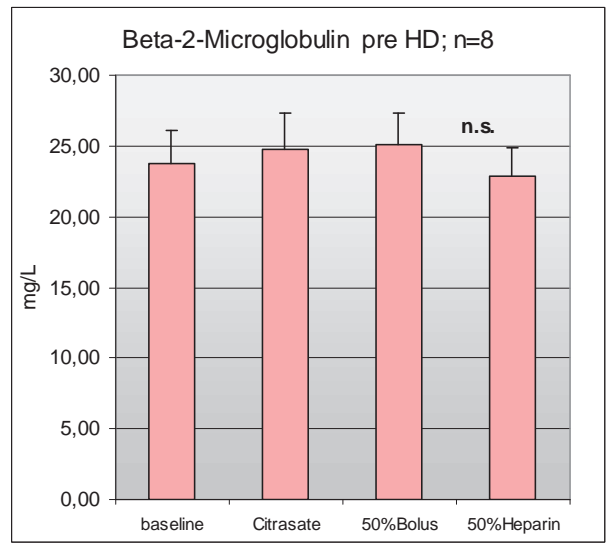

Figure 3. Pre dialysis beta-2-microglobulin during the different study phases.

citrate anticoagulation (Opatrný et al., 2007). A significant reduction of complement activation can be expected if the iCa concentration decreases to $<0.2 \mathrm{mmol} / \mathrm{l}$ (Hartmann et al., 2006). According to Opatrný, the iCa concentration of $0.4 \mathrm{mmol} / \mathrm{l}$, which is usually found during citrate anticoagulation, does not guarantee a decrease of thrombogenicity and complement activation. Therefore, a distinct influence on the decrease in leucocytes cannot be expected during dialysis with Citrasate ${ }^{\circledR}$. Nevertheless, according to Polakovic et al. (2010), a significant decrease of leucocyte count was observed during application of Citrasate ${ }^{\circledR}$. In our investigations a similar trend was visible, which was not significant, however. After decrease of heparin dosage this trend disappears (fig. 4):

The likewise measured levels of albumin and hsCRP were stable during all study phases. However, with regard to myeloperoxidase (MPO), a significant influence was found. 


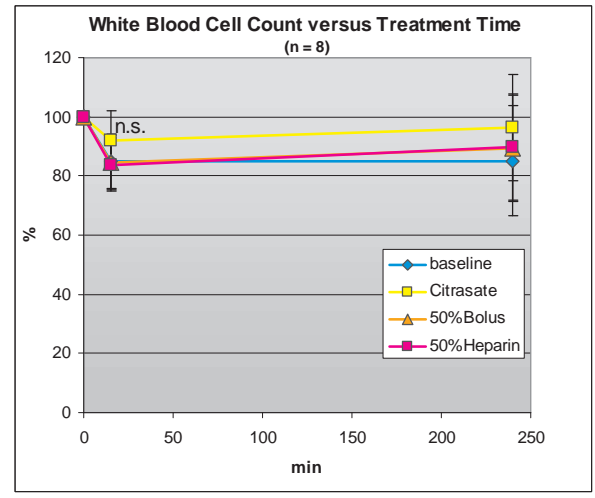

Figure 4. Leucocyte drop during HFD treatments in different study phases

MPO is considered an important parameter of biocompatibility and mortality during dialysis treatment (Borawski et al., 2006, Hörl, 2008, Gritters et al., 2006). MPO is part of the family of heparin-binding proteins. Additionally, MPO is contained in granulocytes, monocytes, macrophages and is also located along the vessel walls (e.g. Hörl, 2008). MPO is considered to be a marker of degranulation of neutrophils and, therefore, also as a parameter of biocompatibility of dialysis and oxidative stress (Borawski et al., 2006). During hemodialysis, the value of MPO increases by more than $100 \%$ (Gritters et al., 2006). MPO release can be inhibited by regional citrate anticoagulation, which suggests a strong influence of heparin on the degranulation of neutrophils. According to a review of Hörl (2008), MPO induces vascular complications by a variety of mechanisms:

- Inhibition of NO-dependent vasorelaxation.

- Production of endogenous NO-inhibitors.

- Oxidation of LDL with consecutive increased absorption in local macrophages.

- Production of reactive species.

The plasma levels of MPO are associated with atherosclerotic vascular complications as well as with the mortality of hemodialysis patients and the general population (Hörl, 2008).

The measured values of MPO show a strong increase 15 min after start of treatment (fig.5). After the change from standard dialysate to Citrasate ${ }^{\circledR}$, no significant changes can be observed, but a tendency can be seen towards lower values after $15 \mathrm{~min}$. The reduction of heparin dosage, however, causes a significantly smaller increase of MPO values as well as a tendency towards lower values before and after dialysis.

\subsubsection{The influence of Citrasate ${ }^{\circledR}$ on the plasma levels of calcium and phosphate}

The complex formation between Ca-ions and citrate causes a decrease of ionized calcium (iCa) in the plasma. After the metabolization of citrate, one part of iCa returns into the blood plasma. 


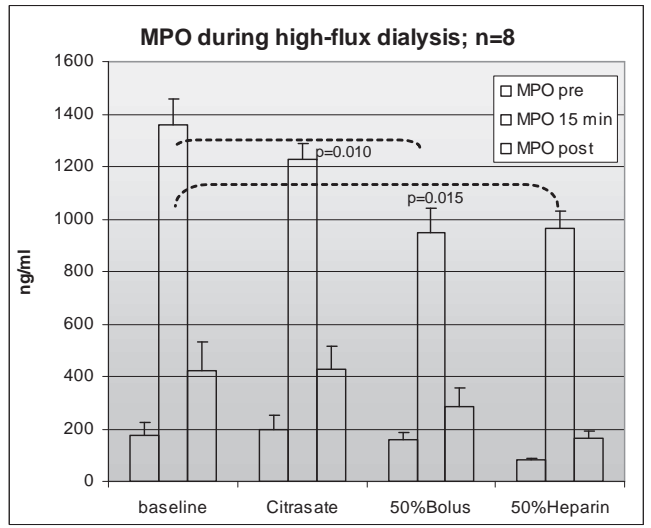

Figure 5. Myeloperoxidase during different study phases of HFD

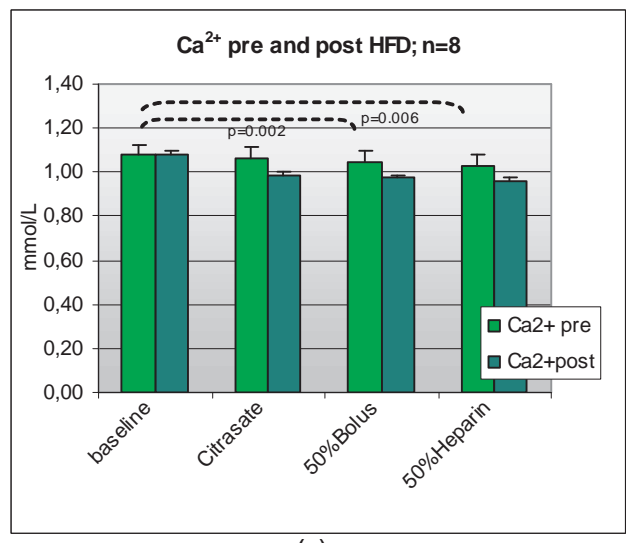

(a)

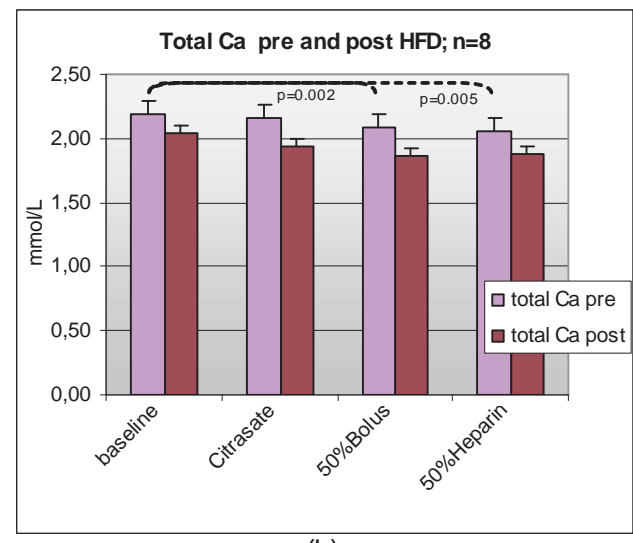

(b)

Figure 6. a, b. iCa and total calcium before and after dialysis during the different study phases of HFD

The other part of calcium-citrate-complex will be removed by means of dialysis. Therefore, a decrease of iCa can be observed during dialysis treatment, as shown in fig.6a.

The mean decrease of iCa amounts to $7 \%$ for all treatments with Citrasate ${ }^{\circledR}$, as can be seen in fig. 6a. The decrease of total calcium is shown in fig.6b. A decrease of total calcium can be observed also during treatments with standard concentrate, but it is more pronounced for treatments with Citrasate ${ }^{\circledR}$ (baseline: - 7\%; Citrasate $^{\circledR}$ : $-9 . .-11 \%$ ).

The drop of iCa was also observed in the same magnitude from other users of Citrasate ${ }^{\circledR}$ (Sands et al., 2012), at least if the concentration of calcium was $1.25 \mathrm{mmol} / \mathrm{l}$. With a calcium concentration of $1.5 \mathrm{mmol} / \mathrm{l}$ in Citrasate ${ }^{\circledR}$, the iCa drop was smaller (e.g. Leimbach et al., 2011, Polacovic et al, 2010). 




Figure 7. Calcium GAP during different study phases of high-flux dialysis

Compared with values of standard dialysis (baseline), the statistically significant decrease of pre-dialysis total Ca (see fig. $6 \mathrm{~b})$ results in values below the standard values $(2.2 \ldots 2.65 \mathrm{mmol} /$ 1). Because of a possible hypocalcemia, it is recommended to perform treatments with Citrasate ${ }^{\circledast}$ with a calcium concentration of $1.5 \mathrm{mmol} / \mathrm{l}$ in the dialysate (see also Polacovic et al., 2010).

The danger of an accumulation of citrate during the dialysis treatment does not exist under the given conditions. The accumulation of citrate can be expressed by the Ca-GAP:

$$
\text { Ca-GAP }=(\text { totalCa post }- \text { totalCa pre })-(\text { iCa post }- \text { iCa pre })(\text { Gabutti et al., 2009) }
$$

If the metabolization of citrate is quick, the Ca-GAP becomes $<0.2$ (Gabutti et al., 2009). As fig. 7 shows, this condition was fulfilled in case of dialysis with Citrasate ${ }^{\circledR}$ :

Regarding the likewise measured phosphate, it can be stated that the phosphate elimination was effective with approx. $70 \%$ and did not differ between the different periods of the study.

\subsection{Online hemodiafiltration in pre- and postdilution mode}

\subsection{1. olHDF in predilution mode}

\subsubsection{Objectives}

In addition to the study with high-flux dialysis (HFD), it should be investigated if Citrasate ${ }^{\circledR}$ concentrate can be used also for on-line hemodiafiltration (olHDF). Since the infusate for olHDF will be prepared directly from the dialysate, the use of Citrasate ${ }^{\circledR}$ dialysate means the infusion of a considerable amount of citrate directly into the blood. Using olHDF in predilution mode, the substitution fluid will be infused into the blood before the dialyzer, which means citrate will be included in the mass transfer processes of the dialyzer. During olHDF in postdilution mode, the infusion of citrate containing fluid takes place behind the dialyzer into the peripheral blood of patients. Since the effects of Citrasate ${ }^{\circledR}$ on free calcium ion concentration 
and coagulation system cannot be precisely predicted, Citrasate ${ }^{\circledR}$ was applied at first in the predilution mode of olHDF.

During the Citrasate ${ }^{\circledR}$ application in olHDF predilution, the focus was directed to the following questions:

- Is it possible to maintain the $50 \%$ reduced heparin dose?

- Can the influence of Citrasate ${ }^{\circledR}$ on the coagulation processes inside the dialyzer increase the efficacy of dialysis?

- Is it possible to reduce the MPO activation as well, as found in high-flux hemodialysis?

- Will the plasma concentrations of calcium and phosphate stay within the physiologically optimal range?

Time schedule, materials, methods, patients and parameters were as described in section 2.

\subsubsection{Results and discussion}

The olHDF study was started with reduced doses of heparin (-50\% for bolus and $-50 \%$ for maintenance dose) determined in the previous HFD study. This was possible without any problems for the baseline treatments (week 1 with HD and Citrasate ${ }^{\circledR}$ ). After transition to olHDF in predilution with Citrasate ${ }^{\circledR}$ and a dialyzer FX100 with a larger surface area, it was necessary to increase the heparin dose for some patients. For one patient, the baseline dose had to be restored. For all other patients, the heparin dose remained $-20 \ldots-50 \%$ lower even if the predilution HDF was performed with acetate-containing standard concentrate.

Figures 8 and 9 show the results regarding the impact of olHDF in predilution on treatment efficacy. For small molecular substances such as urea or creatinine, an increase of efficacy cannot be expected after transition from HFD to olHDF especially for the predilution mode (Ahrenholz et al., 1997). Therefore, the determination of dialysis dose (spKt/V or eqKt/V) in fig. 8a shows no significant changes between the different treatment modes of study.

For medium-sized molecules such as beta-2-microglobulin, the treatment with olHDF is more effective than with HFD because of the larger part of convective transport. Accordingly, the reduction rate of beta-2-m increases from $66.6 \%$ to $70.5 \%$ after changing from HFD to olHDF. However, because of the large spread of HFD values, this change does not become significant. After changing from HFD with Citrasate ${ }^{\circledR}$ to olHDF with standard concentrate, a significant decrease of the beta- $2-m$ reduction rate by $2 \%$ was observed $(p=0.03)$ despite the small sample size. From this result, it can be presumed that the Citrasate ${ }^{\circledR}$ dialysate and -infusate perhaps reduces thrombus formation inside the hollow fibers of the dialyzer.

The time course of the myeloperoxidase (MPO) concentration during treatments with Citrasate ${ }^{\circledR}$ corresponds to the one of the HFD study baseline period (see fig. 5). Compared with this result, figure 10 shows an increase of the $15 \mathrm{~min}$ value during predilution olHDF with Citrasate $^{\circledR}$ and, once more, during predilution olHDF with standard concentrate, which was not statistically significant. The stepwise increase in the heparin dose seems to be the reason for this observation (see fig. 11). A correlation between activation of MPO and heparin 


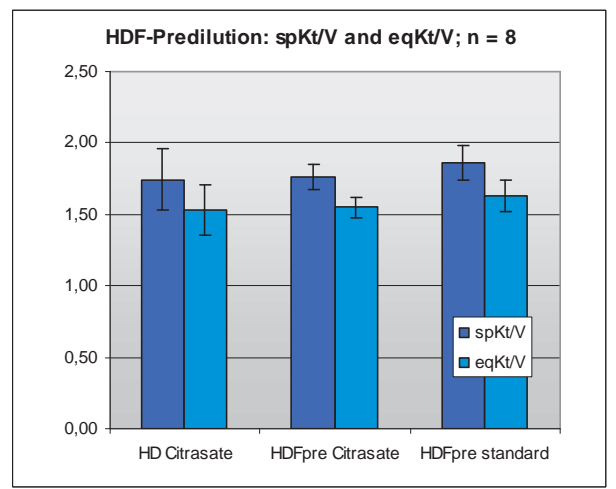

Figure 8. Single-pool and equilibrated Kt/V for treatments with HFD with Citrasate ${ }^{\star}$ and predilution olHDF treatments with Citrasate and standard concentrate

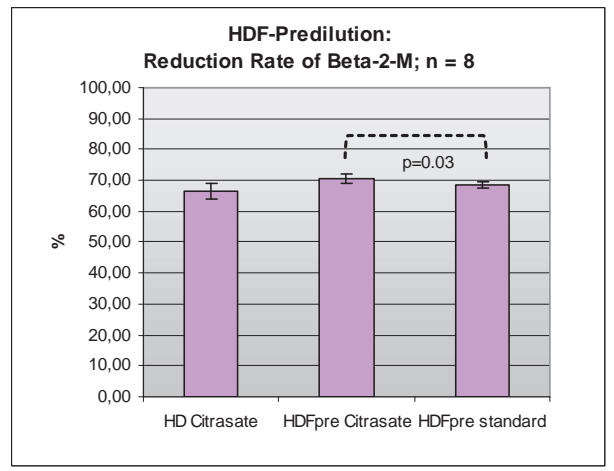

Figure 9. Reduction rate of beta-2-m for HFD treatments with Citrasate ${ }^{*}$ and predilution olHDF treatments with Citrasate $^{\circ}$ and standard concentrate

concentration in blood was found also in some other investigations addressing extracorporeal blood purification (Hörl, 2008, Gritters et al., 2006, Daphna et al., 1998).

As a result of the HFD study with $1.25 \mathrm{mmol} / \mathrm{l}$ calcium in the citrate-containing dialysate, the calcium concentration had to be raised to $1.50 \mathrm{mmol} / \mathrm{l}$ (concentrate MTN 413/415). As shown in fig.12, the calcium concentrations reach a mean level of $1.09 \mathrm{mmol} / \mathrm{l}$ after treatment. The same observations could be made in case of predilution olHDF with standard dialysate $\left(\mathrm{Ca}^{2+}\right.$ : $1.25 \mathrm{mmol} / \mathrm{l})$. Patients usually treated with standard concentrate with $1.25 \mathrm{mmol} / \mathrm{C} \mathrm{Ca}^{2+}$ should obtain $1.50 \mathrm{mmol} / \mathrm{l} \mathrm{Ca}^{2+}$ after changing to Citrasate ${ }^{\circledR}$. This increase becomes necessary to compensate for the iCa-losses resulting from calcium-citrate complex formation.

As shown in fig. 13, the total calcium concentration stays constant at $1.50 \mathrm{mmol} / \mathrm{l}-\mathrm{Ca}^{2+}-$ Citrasate $^{\circledR}$ during HFD and predilution olHDF, whereas the values after treatment with standard concentrate $\left(\mathrm{Ca}^{2+}: 1,25 \mathrm{mmol} / \mathrm{l}\right)$ are reduced by about $9 \%$. This phenomenon can be 


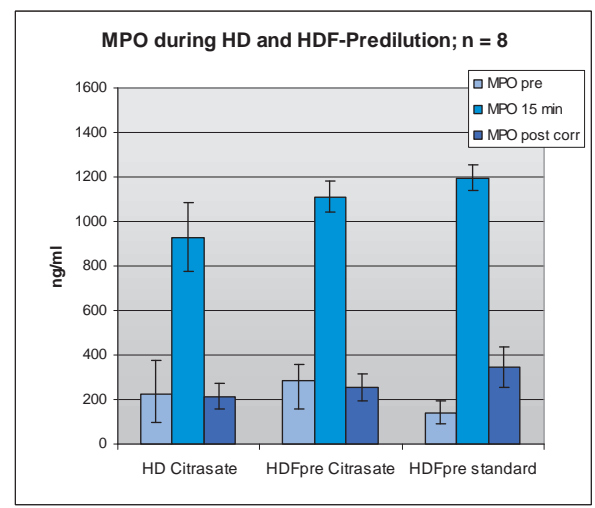

Figure 10. Myeloperoxidase concentrations pre-treatment, after 15 min and post-treatment for HFD and olHDF with Citrasate $^{\circ}$ and olHDF with standard concentrate

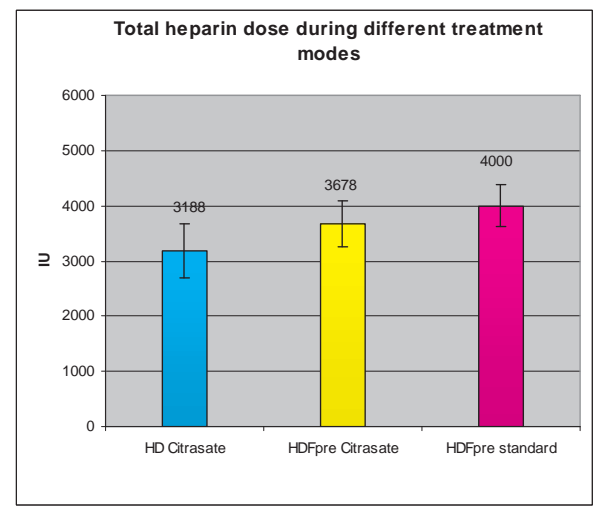

Figure 11. Total heparin dose for HFD and olHDF with Citrasate ${ }^{\circ}$ and olHDF with standard concentrate

explained by the release of free calcium ions from the calcium-citrate complex due to citrate metabolism inside the bloodstream.

The balance between changes of total $\mathrm{Ca}$ and iCa during treatments can be expressed as CaGAP (see equation 5). The value of Ca-GAP should be less than +0.2. Fig. 14 shows that on average, this condition was fulfilled.

\subsection{2. olHDF in postdilution mode}

\subsubsection{Objectives}

Following previous studies on the suitability of Citrasate ${ }^{\circledR}$ concentrate for high-flux hemodialysis (HFD) and online hemodiafiltration in pre-dilution mode (olHDF-pre), it should now 




Figure 12. iCa concentrations pre and post treatment for different treatment modes with and without Citrasate*

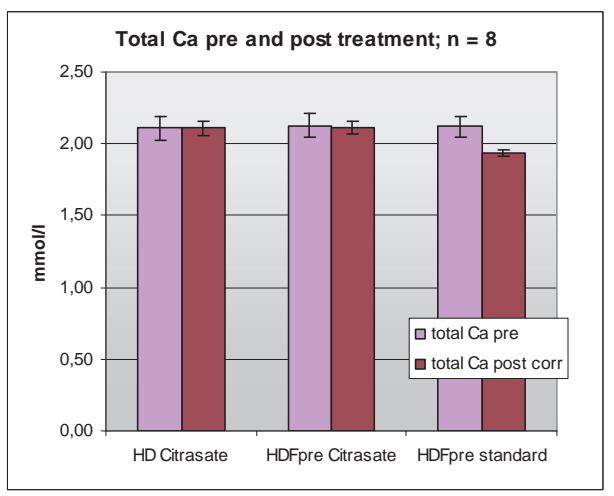

Figure 13. Total Ca concentrations pre and post treatment for different treatment modes with and without Citrasate

be investigated whether the use of citrate-containing dialysate can cause problems during olHDF in postdilution mode (olHDF-post).

In contrast to olHDF-pre, the infusion of citrate-containing solution with olHDF-post occurs behind the dialyzer, i.e. directly into the peripheral blood of the patient, so that the physiological effects are more difficult to assess.

As with olHDF-pre, the main focus of Citrasate ${ }^{\circledR}$ application for olHDF-post should be whether:

- The reduced dose of heparin can be maintained,

- The influence on coagulation processes in the dialyzer leads to improved effectiveness,

- The MPO activation can be reduced in the same way as was possible with HFD,

- The plasma concentrations of calcium and phosphate can remain within the physiologically optimal range. 


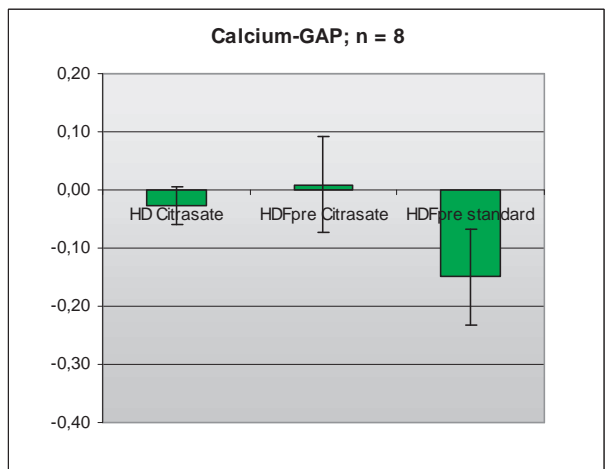

Figure 14. Ca-GAP for different treatment modes with and without Citrasate

Time schedule, materials, methods, patients and parameters were as described in section 2 . One patient dropped out after the olHDF-pre study ( $\mathrm{n}=7$ during the olHDF-post investigations).

\subsubsection{Results and discussion}

The investigation was continued with the heparin dosages from the prior olHDF-pre study (the baseline dose was reached again in one patient, whereas with the remaining patients, the dose even for olHDF employing standard concentrate was $20 \ldots 50 \%$ lower; see section 3.1.1.2).

The comparison of the activated prothrombin time (aPTT) between olHDF-post with Citrasate ${ }^{\circledR}$ and olHDF-post with standard concentrate showed that Citrasate ${ }^{\circledR}$ had no influence on systemic coagulation.

While with olHDF employing predilution, there was no significant difference regarding the removal of low molecular weight substances such as urea compared to HFD, olHDF employing post-dilution was more effective than HFD. However, a difference in effectiveness between the olHDF post-treatment with Citrasate ${ }^{\circledR}$ and standard concentrate could not be found (see Fig. 15). Regarding the removal of beta-2-microglobulin, an improvement in effectiveness compared to HFD could be seen, but a difference between the olHDF-post with Citrasate ${ }^{\circledR}$ and standard concentrate, as was seen in the predilution treatments, could not be determined here (see Fig. 16).

MPO is one of the most important predictors for compatibility and mortality for dialysis treatments. In the previous HFD study, there were significant differences between the individual study phases. Therefore, MPO was measured again at different time points (before treatment, after $15 \mathrm{~min}$ of treatment, and after treatment). As with the olHDF in predilution, there was no significant difference in MPO activation for treatments with Citrasate ${ }^{\circledR}$ or standard concentrate. The MPO values after treatment start tended to be somewhat larger for olHDF-post treatments (probably not significant due to the small number of cases). This is most likely due to the much greater ultrafiltration and therefore, also to the greater dilution of blood with infusion solution employing olHDF-pre $(150 \mathrm{ml} / \mathrm{min}$ versus $60 \mathrm{ml} / \mathrm{min})$. 


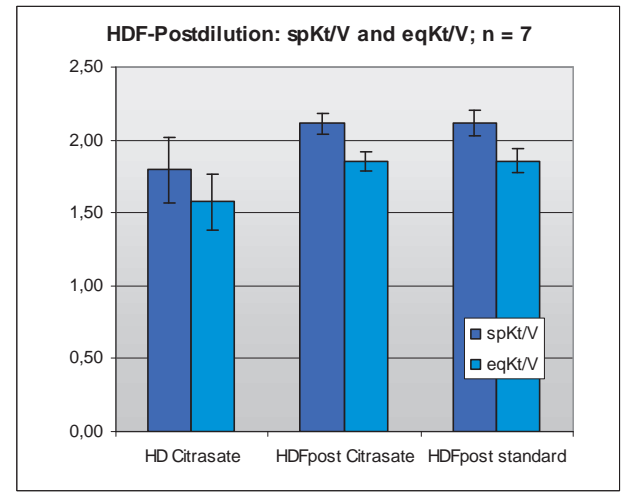

Figure 15. Single-pool and equilibrated Kt/V for treat-ments with HFD with Citrasate $^{*}$ and olHDF-post treatments with Citrasate" and standard concentrate

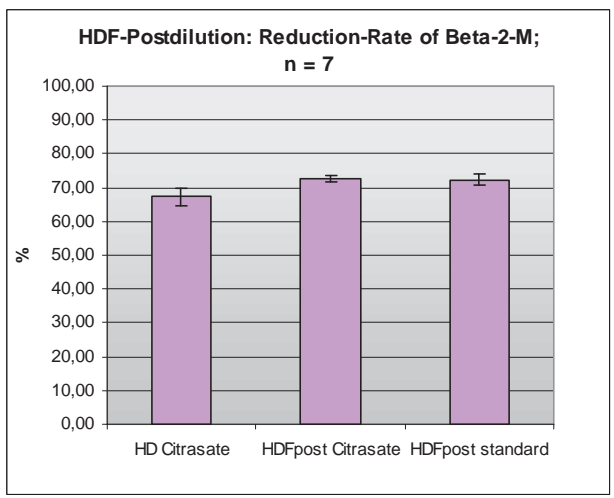

Figure 16. Reduction rate of beta-2-m for HFD treatments with Citrasate and olHDF-post treatments with Citrasate and standard concentrate

Since the heparin dose was constant for all olHDF treatments, an effect of heparin concentration on MPO activation as the one seen in the previous olHDF-pre study could not be observed (comparison MPO during olHDF-pre and -post: see fig. 17a, b.).

As a result of the HFD study with $1.25 \mathrm{mmol} / \mathrm{C} \mathrm{Ca}^{2+}$ in the dialysate, the $\mathrm{Ca}^{2+}$ concentration was raised to $1.50 \mathrm{mmol} / \mathrm{l}$ (concentrate MTN 413/415). As shown in Fig 18a, b., the $\mathrm{Ca}^{2+}$ concentrations of the individual patients level out to values of about $1.10 \mathrm{mmol} / \mathrm{l}$ after treatment, just as in the case of olHDF treatments with normal dialysate $\left(\mathrm{Ca}^{2+}: 1.25 \mathrm{mmol} / \mathrm{l}\right)$. Losses of ionized calcium by chelation were adequately compensated by choosing a higher dialysate $\mathrm{Ca}^{2+}$ for olHDF both in pre- or post-dilution.

The balance between the changes in total calcium and the iCa during treatment can be expressed by the Ca GAP (see equation 5, sections 3.1.3 and 3.1.1.2): 




(a)

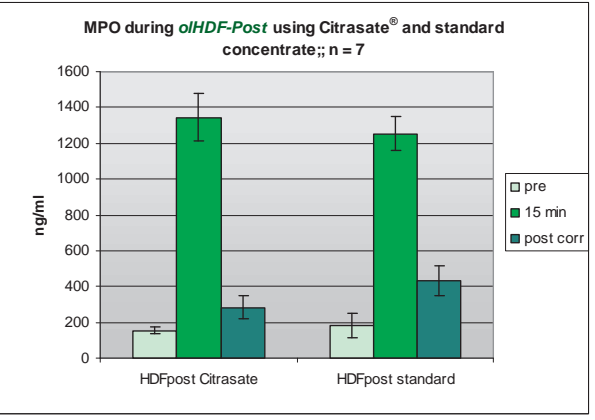

(b)

Figure 17. a, b. Comparison of the MPO values during olHDF with pre- and postdilution (same patient group, constant heparin dose)

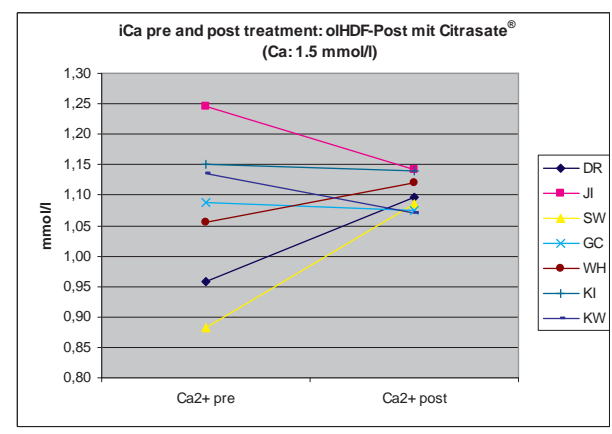

(a)

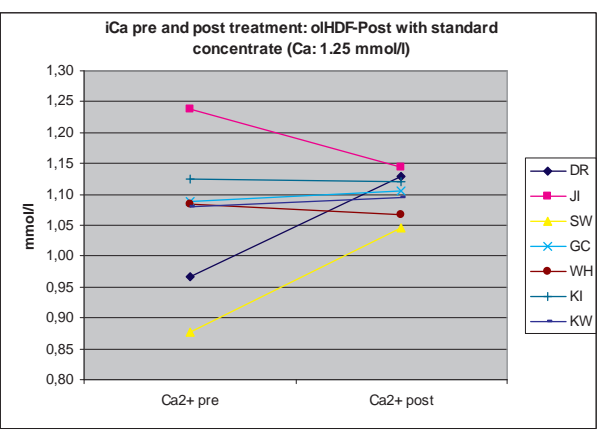

(b)

Figure 18. a, b. Comparison of the individual plasma $\mathrm{Ca}^{2+}$ concentrations during olHDF-post with Citrasate ${ }^{\circ}(1.5$ $\left.\mathrm{mmol} / \mathrm{l} \mathrm{Ca}^{2+}\right)$ and standard concentrate $\left(1.25 \mathrm{mmol} / \mathrm{l} \mathrm{Ca}^{2+}\right)$

Figure 19 shows that with olHDF-post, there is no positive balance for total calcium. Accordingly, no surplus amount of bound Ca remains in the bloodstream, which would indicate an incomplete metabolism of the calcium citrate. According to studies by Bauer et al. (2005), this is also not to be expected. In that study, citrate kinetics during citrate anticoagulation were investigated both in patients with normal renal function and those on hemodialysis. It was found that citrate is also metabolized adequately with renal failure, as well as with mild hepatic dysfunction. Only in patients with severe liver failure is citrate anticoagulation not indicated. If one considers that with citrate anticoagulation the citrate infusion rate is about 0.3 $\mathrm{mmol} / \mathrm{kg} / \mathrm{h}$, while with olHDF in post dilution with Citrasate ${ }^{\circledR}$ dialysate it is only about 0.04 $\mathrm{mmol} / \mathrm{kg} / \mathrm{h}$, then problems arising from incomplete citrate metabolism are not to be expected (example: olHDF-post: $0.8 \mathrm{mmol} / \mathrm{l}$ citrate, infusion rate $3.6 \mathrm{l} / \mathrm{h}, 70 \mathrm{~kg}$ patient).

The calcium-phosphate balance is determined largely by parathyroid hormone. Disruptions of the balance due to non-physiological treatment conditions would therefore be reflected in 


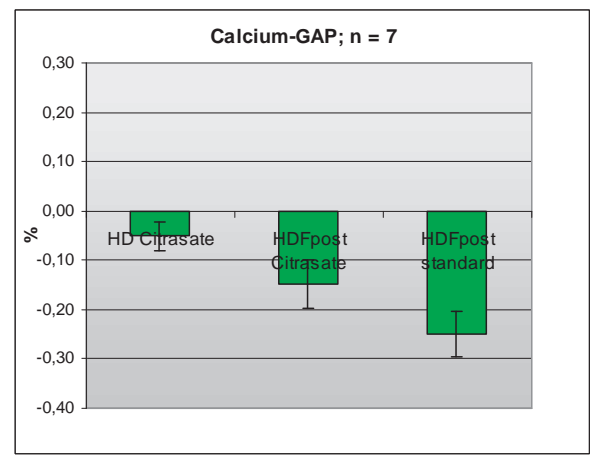

Figure 19. Calcium GAP for the different study phases HFD, olHDF-post with Citrasate ${ }^{\star x}$ and standard concentrate

the concentrations of $\mathrm{Ca}^{2+}$, phosphate and PTH. As shown in Figures 20 and 21, however, no significant differences between olHDF-post treatments with Citrasate ${ }^{\circledR}$ and standard concentrate were observed.

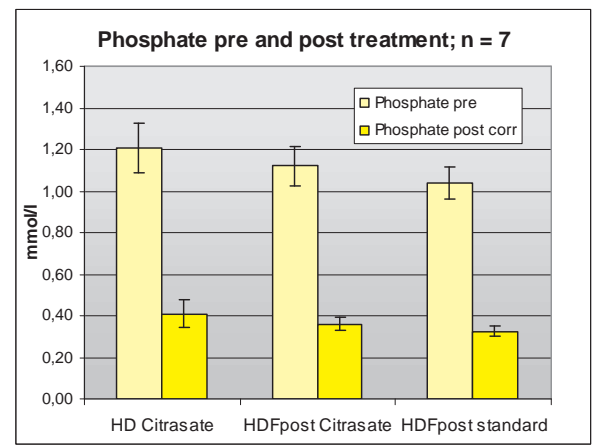

Figure 20. Plasma phosphate concentrations pre and post treatment for different treatment modes: HFD with Citrasate", olHDF-postdilution with Citrasate ${ }^{*}$ and standard concentrate

Regarding other measured parameters such as bicarbonate $\left(\mathrm{HCO}_{3}^{-}\right), \mathrm{Na}^{+}, \mathrm{K}^{+}$, there were no significant differences in the individual study phases. The mean ESA (Aranesp ${ }^{\circledR}$ ) and iron intake (Ferrlecit) remained constant during all study phases. 


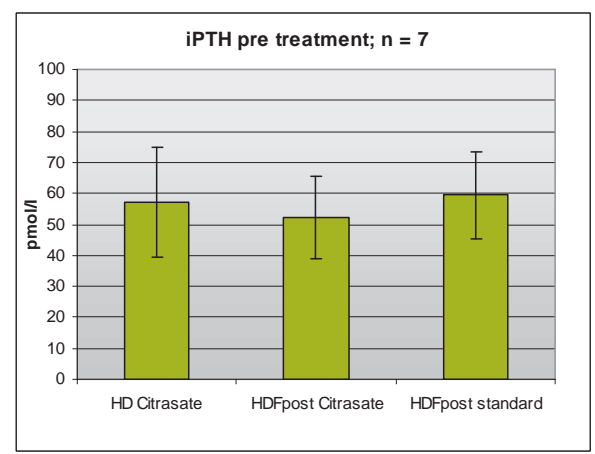

Figure 21. iPTH pre treatment for different treatment modes: HFD with Citrasate ${ }^{\circ}$ and standard concentrate Citrasate, olHDF-postdilution with

\section{Summary}

\subsection{High-flux dialysis (HFD)}

Using Citrasate ${ }^{\circledR}$ for HFD treatments, the results can be summarized as follows:

- A reduction of total heparin dose by $50 \%$ was possible (50\% bolus and $50 \%$ maintenance amount) without increase of clotting events in the dialyzer or extracorporeal circuit and without change of treatment efficacy $(\mathrm{Kt} / \mathrm{V})$.

- An influence of Citrasate ${ }^{\circledR}$ on sensitive inflammation parameters such as beta-2-microglobulin, hsCRP and serum albumin was not detected. MPO has reacted sensitively as marker for granulocyte degranulation and oxidative stress on the reduction of heparin dosage.

- The plasma level of phosphate was not influenced by the application of Citrasate ${ }^{\circledR}$.

- A reduction of ionized calcium and total calcium was observed during application of Citrasate ${ }^{\circledR}$. The reduction of total calcium was found to be partially below the normal range. Therefore, it has to be recommended to use $1.50 \mathrm{mmol} / \mathrm{l} \mathrm{Ca}^{2+}$ instead of $1.25 \mathrm{mmol} / \mathrm{C} \mathrm{Ca}^{2+}$, which is common for standard dialysate. The Ca-GAP was found to be sufficient small, therefore a quick metabolization of citrate can be assumed.

In conclusion, the study has demonstrated that Citrasate ${ }^{\circledR}$ can be applied for high-flux dialysis, saving heparin and increasing the biocompatibility of treatment by reduction of oxidative stress.

\subsection{Online hemodiafiltration with predilution (olHDF-pre)}

The results can be summarized as follows:

- Several patients could be treated in this investigation with the $50 \%$ reduced total heparin dose, just as during the previous HFD study. This reduced total heparin dose, however, 
could not be maintained for all patients under the conditions of larger surface areas for dialyzers (FX100) during olHDF predilution.

- The beta-2-microglobulin elimination was slightly, but significantly, increased in comparison to standard concentrate. For urea, however, the efficacy could not be improved by olHDF predilution as expected.

- The activation of myeloperoxidase (MPO) corresponded to the values of the previous HFD study with Citrasate ${ }^{\circledR}$. An increase in mean heparin dosage was connected with an increase in MPO concentration.


the one of standard dialysate with $1.25 \mathrm{mmol} / 1 \mathrm{Ca}^{2+}$ after raising dialysate calcium from 1.25 to $1.50 \mathrm{mmol} / \mathrm{l}$.

- The mean plasma concentrations of phosphate and iPTH remained at the same level during all periods of study. The small size of Ca-GAP means that disturbance of Ca-phosphate balance did not occur because of the high infusion rate of citrate-containing infusion fluid and because of the sufficiently quick metabolism of citrate.

In conclusion, the study has demonstrated that Citrasate ${ }^{\circledR}$ can be applied also for online Hemodiafiltration (olHDF) with predilution mode. As found during high-flux dialysis as well, Citrasate $^{\circledR}$ saves heparin and increases the biocompatibility of treatment by reduction of oxidative stress.

\subsection{Online hemodiafiltration with postdilution (olHDF-post)}

In summary, it can be stated that:

- The doses of heparin from the previous olHDF-pre study could be maintained also with olHDF-post. The baseline dose at the beginning of all three studies had to be re-administered in one case; with the remaining 6 patients, a $20 \ldots 50 \%$ reduced total heparin dose could be administered. However, this was also possible with the olHDF post-treatment using standard concentrate.

- As expected, the treatment effectiveness was improved both in terms of the $\mathrm{Kt} / \mathrm{V}$ values and the beta-2-m removal rate compared to HFD. However, no differences between the olHDFpost treatments with either Citrasate ${ }^{\circledR}$ or standard concentrate could be identified.

- Regarding the activation of myeloperoxidase (MPO), there were no significant differences between treatments with Citrasate ${ }^{\circledR}$ and standard concentrate. Compared to the treatments with olHDF-pre, with postdilution olHDF the MPO values tended to be somewhat larger, which is presumably due to the higher dilution of the blood with HDF-pre.

- After increasing the dialysate calcium from 1.25 to $1.50 \mathrm{mmol} / \mathrm{l}$ compared to the first study (HFD), the course of the ionized Ca during Citrasate ${ }^{\circledR}$ HFD and olHDF-post with Citrasate $^{\circledR}$ corresponded to the one of olHDF-post with normal dialysate and $1.25 \mathrm{mmol} / \mathrm{C} \mathrm{Ca}^{2+}$.

- The mean plasma concentrations of phosphate and iPTH were at about the same level in all study phases. As with the significant shortfall of the Ca-GAP at 0.2 , this means that 
disruptions of the Ca-phosphate balance by the high infusion rate of citrate containing substitute infusions did not occur and that there was a sufficiently rapid metabolism of citrate.

\section{Author details}

Roland E. Winkler ${ }^{1}$, Peter Ahrenholz ${ }^{2}$, Wolfgang Paetow ${ }^{1}$, Grit Waitz ${ }^{2}$ and Hartmut Wolf ${ }^{3}$

1 Praxisverbund für Dialyse und Apherese, Rostock, Germany

2 BioArtProducts GmbH, Rostock, Germany

3 Biomedical Consulting, Hohen Neuendorf, Germany

\section{References}

[1] Kossmann, R. J, \& Callan, R. Ahmad S: Fifty five percent heparin reduction is safe with citrate dialysate in chronic dialysis patients, ASN's $39^{\text {th }}$ Annual Renal Week meeting November (2006).

[2] Kossmann, R. J, Gonzales, A, \& Callan, R. Ahmad S: Increased Efficiency of hemodialysis with Citrate Dialysate, a prospective Controlled study, JASN, (2009). , 4(9)

[3] Gabutti, L, Lucchini, B, Marone, C, \& Alberio, L. Burnier M: Citrate vs. Acetate based Dialysate in Bicarbonate Haemodialysis: Consequences on Haemodynamics, Coagulation, Acid-base status and Electrolytes. BMC Nephrology (2009). , 10

[4] Ouseph, R. Ward RA: Anticoagulation for Intermittent Hemodialysis. Seminars in Dialysis, (2000). , 13(3)

[5] van Beaumont W: Evaluation of hemoconcentration from hematocrit measurements Journal of Applied Physiology, May (1972). , 32(5)

[6] Christiansen TF: Determination of Sodium and Potassium in PlasmaA Comparison between Direct Potentiometry and Flame Photometry. Radiometer Publication, 0000-0906Denmark (1991).

[7] Leimbach, T, Jütterschenke, M, Czerny, J, \& Aign, S. Kron J: Heparin-Einsparung durch Verwendung von citrathaltigem Dialysat? Poster, Kongress für Nephrologie, Berlin (2011). , 10-13.

[8] Ahmad, S, \& Callan, R. Kossmann RJ: Heparin reduction with citrate dialysate. Presented at the European Renal Association-European Dialysis and Transplant Association 
congress, Glasgow, Scotland, July (2006). and published in Nephrology Dialysis Transplantation, Supplement 4, 2006, 21

[9] Sands, J. J, Kotanko, P, Segal, J. H, Ho, C-H, Usvat, L, Young, A, Carter, M, Sergeyeva, O, Korth, L, Maunsell, E, Zhu, Y, \& Krishnan, M. Diaz-Buxo JA: Effects of Citrate Acid Concentrate (Citrasate ${ }^{\circledR}$ on Heparin N Requirements and Hemodialysis Adequacy: A Multicenter, Prospective Noninferiority Trial. Blood Purif (2012). , 199-204.

[10] Craddock, P. R, Fehr, J, Dalmasso, A. P, \& Brighan, K. L. Jacobs HS: Hemodialysis leukopenia. Pulmonary vascular leukostasis resulting from complement activation by dialyzer cellophane membranes. J. Clin. Invest (1977). May; , 59(5), 879-888.

[11] Opatrný Jr KRichtrová P, Polanská K, Wirth J, Sefrna F, Brandl M, Falkenhagen D: Citrate Anticoagulation Control by Ionized Calcium levels Does Not Prevent Hemostasis and Complement Activation During Hemodialysis. Artificial Organs 31(2), (2007).

[12] Hartmann, J, Strobl, K, \& Fichtinger, U. Falkenhagen D: Citrate anticoagulation and activation of the complement system.Poster, ESAO 2006Umea, Sweden

[13] Polakovic, V, \& Lopot, F. Svara F: Citrasate dialysis concentrate. General University Hospital and 1th Medical Faculty of the Charles University, Dept. of Medicine, Prague, Research Report,(2010).

[14] Locatelli, F, \& Manzoni, C. Del Vecchio L, Di Filippo S, Pontoriero G, Cavalli A: Management of Anemia by Convective Treatments. Contributions to Nephrology, H. Kawanishi, A.C. Yamashita, Eds., 168, 162-172.

[15] Winkler, R. E, \& Ahrenholz, P. Freivogel K: Influence of Online Hemodiafiltration on Hemoglobin Level, ESA-Dosage and Serum Albumin- Retrospective, Multicenter Analysis. Progress in Hemodialysis- From Emergent Biotechnology to Clinical Practice. A. Carpi, C. Donadio, G. Tramonti, Eds., published by InTech, 978-9-53307-377-4free online: www.intechopen.com

[16] Ahrenholz, P, Winkler, R. E, Ramlow, W, \& Tiess, M. Müller W: On-line hemodiafiltration with pre- and postdilution: a comparison of efficacy. The International Journal of Artificial Organs/ (1997). (2), 81-90.

[17] Borawski, J, Naumnik, B, \& Rydzewska-rosolowska, A. Mysliwiec M: Myeloperoxidas up-regulation during haemodialysis: is heparin the missing link? Nephrol. Dial. Transplant (April (2006).

[18] Hörl WH: Die Antikoagulation mit Zitrat reduziert die Mortalität und verbessert die Erholung der Nierenfunktion bei Patienten mit akutem Nierenversagen NephroNews, Ausgabe 5/08

[19] Gritters, M. Grooteman MPC, Schoorl M, Bartels PCM, Scheffer PG, Teerlink T, Schalkwijk CG, Spreeuwenberg M, Nubé MJ: Citrate anticoagulation abolishes de- 
granulation of polymorphonuclear cells and platelets and reduces oxidative stress during haemodialysis. Nephrol. Dial. Transplant ((2006).

[20] Daphna, E. M, Michaela, S, Eynat, P, \& Irit, A. Rimon S: Association of myeloperoxidase with heparin: oxidative inactivation of proteins on the surface of endothelial cells by the bound enzyme. Mol Cell Biochem. (1998). Jun;183(1-2):55-61

[21] Maruyama, Y, \& Lindholm, B. Stenvinkel P: Inflammation and oxidative stress in ESRD- the role of myeloperoxidase. J. Nephrol 2004Suppl. , 8, 72-76.

[22] Bauer, E, Derfler, K, \& Joukhadar, C. Druml, W: Citrate Kinetics in Patients Receiving Long-Term Hemodialysis Therapy. Am J Kidney Dis 2005 , 46(5), 903-907.

[23] Ahmad, S, Callan, R, \& Cole, J. J. Blagg CR: Dialysate made from dry chemicals using citric acid increases dialysis dose. Am J Kidney Dis 2000 , 35, 493-499. 